\title{
Anatomical Education Using Marine Products for Elementary School Students
}

\author{
Ayano Omura ${ }^{1 *}$ \\ ${ }^{1}$ Department of Art, Nihon University College of Art, 2-24-1, Asahigaoka Nerima-ku, Tokyo, JAPAN
}

*Corresponding Author: cuttlefish.ayano.o@gmail.com

Citation: Omura, A. (2019). Anatomical Education Using Marine Products for Elementary School Students. Pedagogical Research, 4(4), em0045. https://doi.org/10.29333/pr/5944

Published: September 28, 2019

\begin{abstract}
Anatomical education is very important in understanding the internal structure of the body and the mechanism of life, especially for the medical profession, including nursing. However, in Japan, students have a few opportunities of getting anatomical education using animals before they enter university. The different step-by-step anatomical curriculum needs to be created for elementary school, junior high school, high school, and university students. However, it is difficult to perform anatomical education widely, particularly with bioethics problems and students who often have an aversion to dissected animals. Therefore, it is considered very useful to introduce anatomical education using marine products, which are more familiar. In particular, fish have the same basic structure as vertebrates, so they are useful for understanding the bodies of vertebrate animals, including the human body. Also, the use of marine products other than fish can deepen students' understanding of the structure of organisms of various systems. Therefore, in this study, we conducted anatomical lectures from functional morphology and ecological point of view, using marine products as teaching materials for elementary school children. To prevent students' aversion, the marine products were wrapped, which also reduced the smell. Students actively learned the internal structure of fishes, cephalopods, and shellfish, without aversion. According to our questionnaire survey, most participants reported that their impression and comprehension of the course was excellent or good. The use of "seafood" as teaching material for young learners was found to be very useful for anatomical education.
\end{abstract}

Keywords: anatomy, cephalopods, fish, marine products, scallop, science education

\section{INTRODUCTION}

The medical profession, and nursing, in particular, requires a high level of expertise related to human life. Expert knowledge, accurate judgment, and prompt action are required to address the needs of the patient (Sakashita et al., 2004). Anatomical knowledge of the human body is essential (Sakashita et al., 2004). Especially, the anatomical practice is very important since not only hand-on deep understanding but also the opportunity of understanding "three-dimensional” structure of life (Jang et al., 2017; Tompson and Toga, 1996). The Anatomical practice is also known for providing a forward-looking learning opportunity, the active knowledge needed to become a medical professional, and an analytical view to learners (Lempp, 2005). However, it has been reported that students who have advanced to the nursing system are rarely taught about animal anatomy before joining university (Iwama and Hatogai, 2009).

Therefore, it is vital to create a curriculum in elementary school, junior high school, high school, and at the university level, that allows students to learn about the animal body while exploring its structure and functions (Iwama and Hatogai, 2010). When it comes to animal dissection, however, it is reported that the implementation 
rate is about $10 \%$ in elementary school and $30 \%$ in junior high school (Nishikawa and Tsuruoka, 2007). In addition to bioethical considerations, this is also because of the revulsion that quite a lot of students and instructors feel towards dissection (Iwama and Hatogai, 2010; Iwama, Matsubara and Shimoji, 2008). It has also been reported that male students show a greater dislike for dissection practice (Kato, 2017). The stress on medical students for anatomical practice has many reported (Dinsmore et al., 2001; Finkelstein and Mathers, 1990; Houwink et al., 2004). The aversion for anatomy is reported for the problem and the obstacle to learner's understanding for inner structure of animals (Iwama et al., 2008; Koike and Takatsudo, 2012). When students express aversion towards dissection, it is important to present them with alternative learning methods (Kato, 2017). Thus, when conducting anatomical education for primary scholars, various factors must be considered.

In educating the new student, studies show the importance of introducing content that is perceived as familiar, to make classes interesting (Furihata et al., 2009). Recently, foodstuff has been used for anatomical education because of its familiarity to learners (Kashio, 2016). In anatomy classes for elementary school students, small dried sardines have been used extensively in recent years (Hosoyama, 2012; Saiki, 2017). According to Saiki (2017) research reveals the advantages of studying the internal structure of small dried sardines without special anatomical work. However, when dissecting small fish, such as dried sardines (Engraulis japonicus), dexterity of the hands is required. Further, since the object is small, it is difficult to observe the details (Saiki, 2017).

While dried sardines are easy to use as teaching material, it is difficult to accurately convey what their anatomical form and internal structure look like when they are alive, because their bodies are now shrunken and desiccated. In high schools, squid is being dissected to demonstrate the composition of animal bodies (Saiki and Okino, 2014). Cooked birds are also being used for anatomical education (Nozaki and Katayama, 2017). However, although high school students can use knives in anatomy classes, elementary school students are not allowed to owing to safety concerns. Omura (2016) considers teaching material that can be observed by the naked eye or with a magnifying glass (i.e., with minimal effort), to be ideal. As they constitute anatomical material of an appropriate size, (Sasaki, 2008) recommends fishery products. The use of fish fillets and scallops makes it possible to study animal anatomy while eliminating the need for knives and physical dexterity. Since fish have the basic structure of all vertebrate animals (Romer and Parsons, 1986), this exercise can provide the foundational knowledge necessary for future dissections of mammals and humans. Besides, familiarity with the internal structure of different animals makes it possible not only to recognize biological diversity but also to understand body structures more comprehensively (Iwama et al., 2008). Therefore, it is suggested that a diversity of species may be desirable, especially in the context of anatomical education for children. By showing the internal structure not only of fish but of other invertebrates as well, the impact of the lesson is amplified.

Morphological and functional studies have also proven to be necessary for the field of nursing (Sakashita et al., 2004). The shape of the organism reflects its function, which is also reflected in the internal structure of animals (Romer and Parsons, 1986). However, since anatomy as a subject has much content that must be memorized, it is often caught as an academic record of memorization 2008). Therefore, students must be provided with opportunities to think about the role of that form (Sakashita et al., 2004). In this study, we aimed to use marine products as teaching materials from an anatomical and functional morphological viewpoint, practice education, to verify their usefulness.

\section{MATERIALS AND METHODS}

\section{Course Implementation}

We presented a practice lecture for elementary school students (18 people) at a lifelong learning facility attached to a university (Gakushuin Sakura Academy) in 2018. After delivering a lecture on the ecology of marine life and facilitating the observation of marine products using macroscopic and magnifying glasses, time for a discussion was established.

To evaluate the usefulness of marine products for avoiding learner's aversion, a questionnaire was distributed before and after the course: a five-point scale evaluating the impression for the internal structure of marine lives. The difference in this rate before and after the lecture was evaluated with the Wilcoxon Signed-Rank Test. Besides, to survey the effect of the course, a questionnaire was distributed after the course: a five-point scale evaluating the students' impression of the course and their comprehension levels was assigned to each item. In addition, a free description field under headings such as "understanding" and "difficulty" was included.

\section{Seafood Used in the Course and Commentary}

We chose to use marine products that are typically seen at the dining table, as teaching material. Products whose morphological features and appearance could be observed with the naked eye or the magnifying glass were therefore chosen. 

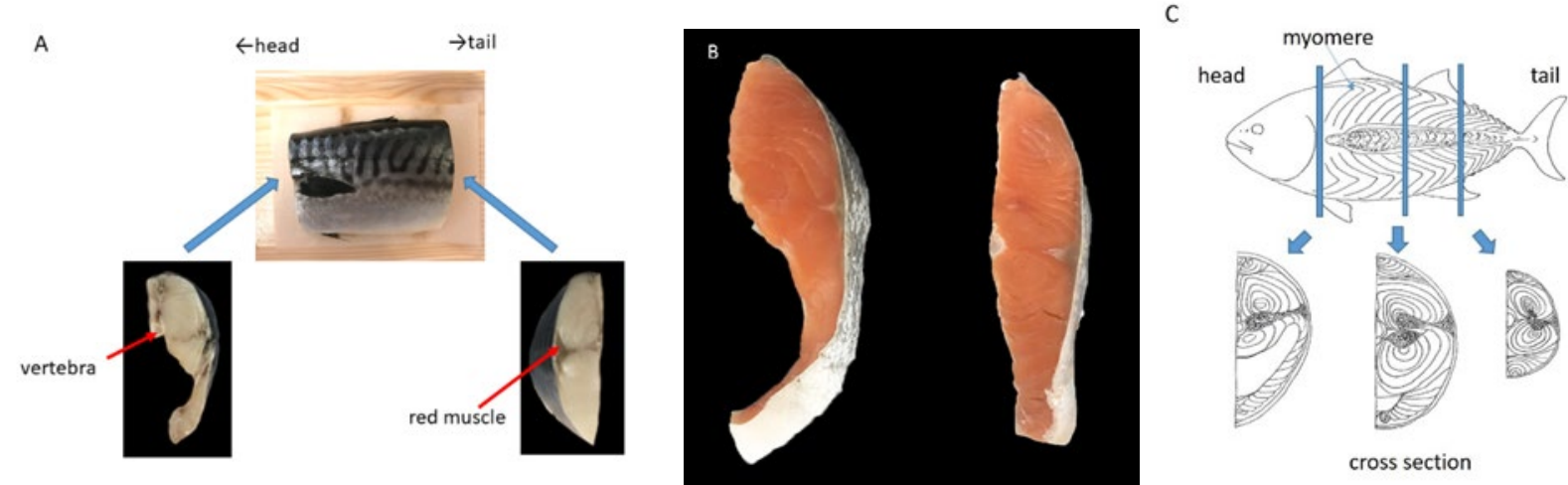

Figure 1. A: The fillet of mackerel and the cross sections of the mackerel. B: The cross sections of the axial muscles of the salmon. C: The axial muscles of a fish.

A

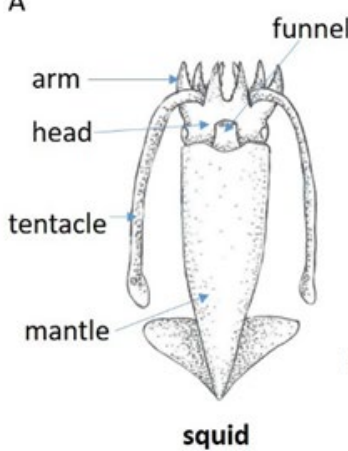

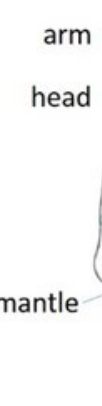

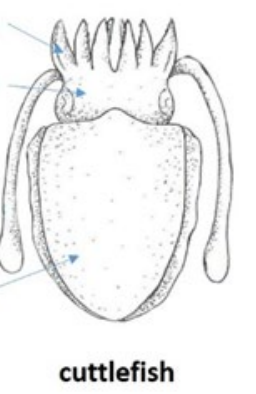

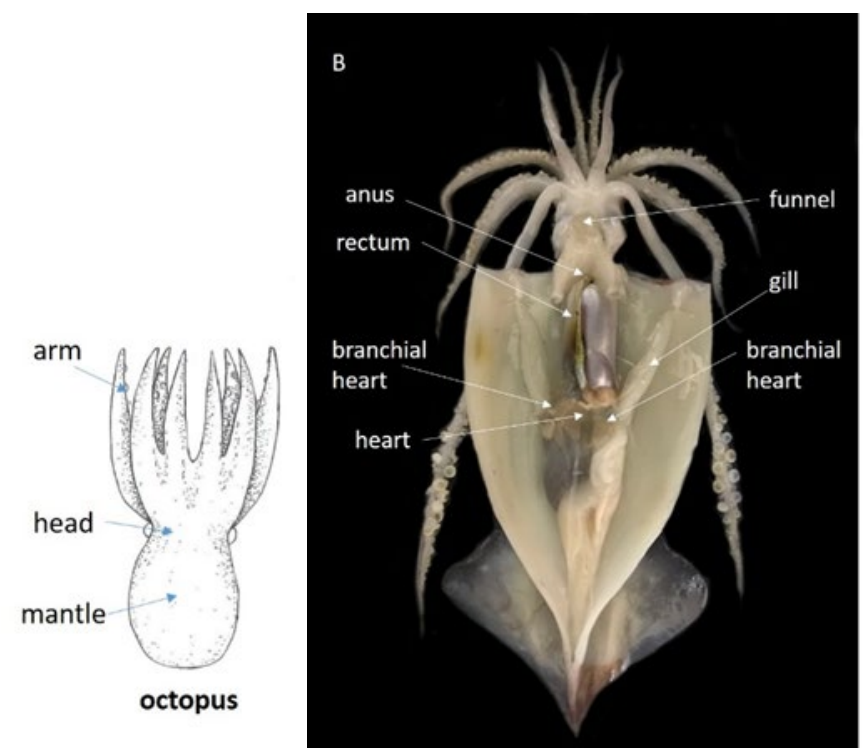

Figure 2. A: Body position of the cephalopods. B: The inner structure of the squid.

\section{EXPLANATION CONTENTS}

\section{Internal Structure and Myology of Fish}

We used a fillet of mackerel (Scomber japonicus) and a fillet of salmon (Oncorbynchus keta) to better understand the fillet as a chunk of "muscle" (Figure 1A, B). The body of a fish is divided into the head, the torso, and the tail. The vertebral column, which is a characteristic of vertebrate animals, passes through the dorsal side. The segmented axial muscle is divided into myomeres by myoseptal connective-tissue partitions (Figure 1C). When swimming, muscles on both the left and right sides are used alternately, the wave motion is transmitted to the back, and the water moves backward. The fillet was presented as a cross-section of the fish trunk, while the patterns visible on the surface of the fillet were described as myoseptal connective-tissue partitions. Furthermore, since internal organs are stored in the body cavity, and as the axial muscles surround the celom, the inward curve of the fillet was attributed to the presence of a celom on the inner surface of the fish.

We also delineated the different types of muscles. Red muscles (slow muscles) are loose but resilient, suitable for sustained swimming. In contrast, white muscles (fast muscles) are powerful but not conducive to sustained swimming. Red streaks are streaks of blood, whose proportions vary depending on ecology (swimming ability).

\section{Basic Posture and Internal Structure of Cephalopods}

To understand the basic body structure of cephalopods, squid (Todarodes pacificus) were used (Figure 2). The cephalopod's arms extend outwards from the head, behind which the mantle is located. Its body posture is different from that of vertebrates. When swimming, water jets out of a funnel (which many people mistake for a mouth); the direction of the funnel decides the direction in which the cephalopod swims. Cephalopods have three hearts; one heart (systemic heart) and two branchial hearts. The heart lies in the almost middle in the body and circulates blood for the whole body. Branchial hearts act as the supplement pump of the systemic heart. Branchial heats 


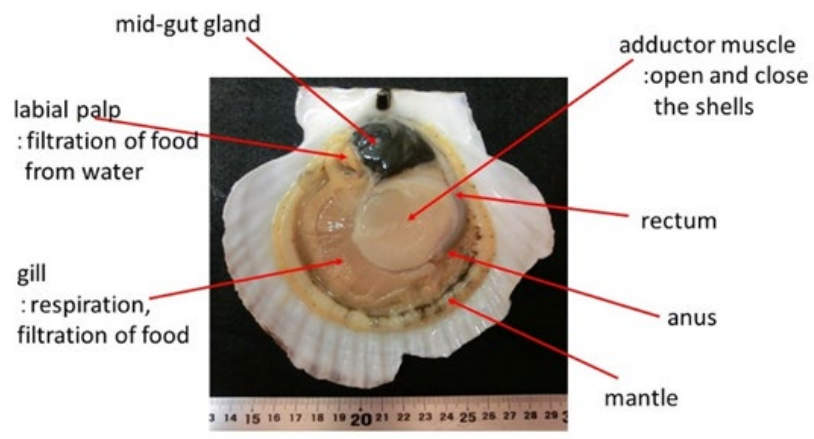

Figure 3. The inner structure of the scallop

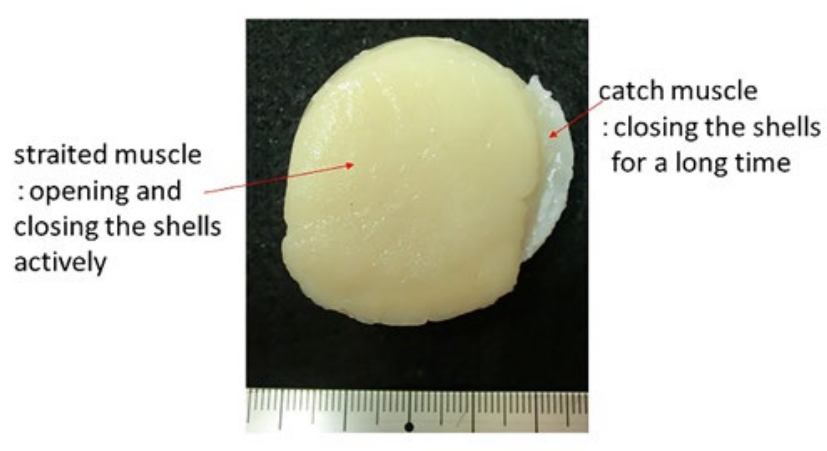

Figure 4. The adductor muscles of the scallop

locate at the basis of the gills, and they help the gas exchange of the gills (Wells, 1992). In the instructional material, a description of the basic structure and movements at the time of swimming are added.

\section{Internal Structure of the Bivalve}

Scallops (Patinopecten yessoensis) were used to understand the internal structure of bivalves (Figure 3). Bivalves are filter feeders. They filter "food"-such as detritus and plankton-from the water using gills and labial palps, and convey it to the mouth. Food coming from the mouth is digested in the stomach, absorbed by the mid-gut gland, and excreted from the intestine through the anus.

We explained the mantle, which is the so-called "Himo" secretes the shell component. The principal or edible parts of the scallop are the adductor muscles, which are of two kinds: a striated muscle to open and close the shell firmly and a catch muscle to keep the shell closed by less energy (Funabara, 2009). The striated muscle is soft, and the catch muscle is hard and elastic (Figure 4). We instructed students to touch and confirm the differences between both types of muscles through the lap seal packaging.

\section{Teaching Materials}

Unlike the science laboratory, the room in which this course was conducted did not have any water supply. Also, because it is a comprehensive lifelong learning institution not only for scientists but also for general people, it is necessary to prevent a strong smell. For that reason, we prepared a sample sealed with lap or Ziploc bag, which allowed the learners to touch the material without getting their hands dirty (Figure 5). 
Figure 5. The wrapped salmon

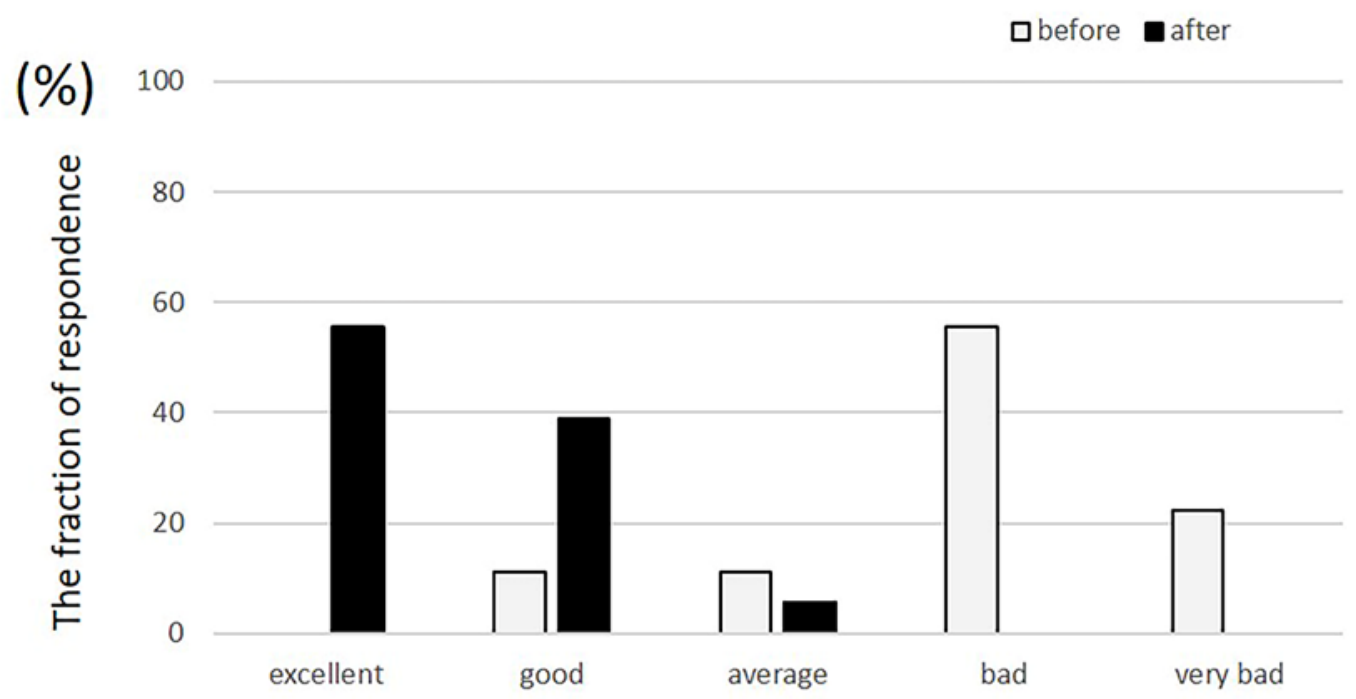

Figure 6. The results of the questionnaire on the impression about the inner structure of animals

\section{RESULTS}

\section{Participants' Situations}

- When we showed them the marine products, the children responded positively, crying out, "that looks delicious!"

- They used a magnifying glass to observe the myosepta pattern of the fish muscles actively.

- Upon seeing the basic body structure of the cephalopods, they were amazed. Since there are many opportunities to see the pop culture drawing whose face is drawn on the torso part, it seems that the exact body structure is not well known.

- By touching the muscles of scallops (through the lap seal packaging), they understood that there were two types of muscles with different degrees of hardness.

\section{Results of the Questionnaire}

Figure 6 shows the results of the questionnaire which was taken before and after the course on the impression about the inner structure of animals. Before the course, 11.1\% (2 out of 18 students) answered that the impression about inner structure of animals was good, $11.1 \%$ ( 2 out of 18 students) answered that the impression was average, $55.6 \%$ (10 out of 18 students) answered bad, $22.2 \%$ (4 out of 18 students) answered very bad. After the course, $55.6 \%$ (10 out of 18 students) answered that the inner structure was excellent, 38.9\% (7 out of 18 students) said it was good, and $5.6 \%$ (1 out of 18 students) said it was average. The significant difference was shown between the impression of the inner structure of animals before the lecture and after the lecture $(p<0.01)$. 
(\%)

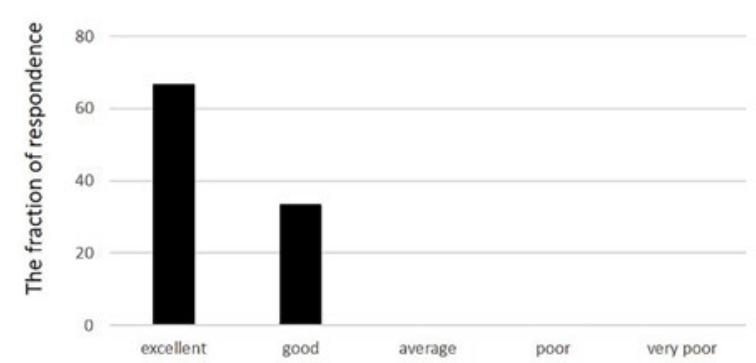

Figure 7. The results of the questionnaire on comprehension of the course

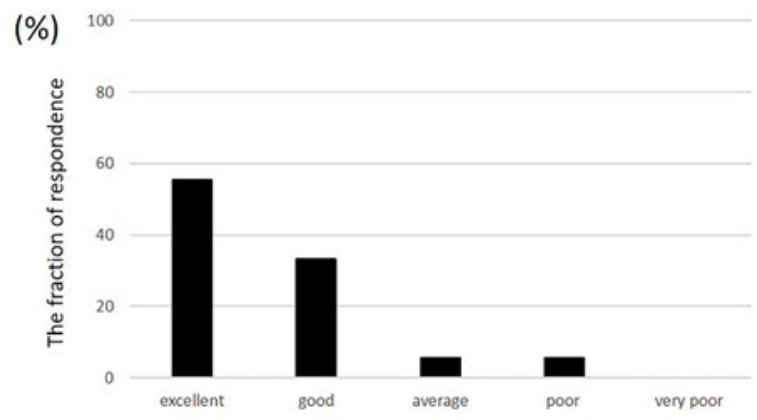

Figure 8. The results of the questionnaire on the impression of the course

Figure 7 shows the results of the questionnaire on comprehension of the course: $66.7 \%$ (12 out of 18 students) said their comprehension levels were excellent, while $33.3 \%$ (6 out of 18 students) said they were good. Figure 8 shows the results of the questionnaire on the impression about the course: $55.6 \%$ (10 out of 18 students) answered that the course was excellent, 33.3\% (6 out of 18 students) said that it was good, 5.6\% (1 out of 18 students) said it was average, and 5.6\% (1 out of 18 students) said that it was poor.

Some good points made in the free description column were: "I came to know that the fillet is a muscle for the first time," "I understood why the fillet is that shape," "It was fun to understand the body structure of cephalopods," "I was glad that I understood that there were mouths and anuses in the shellfish," "It was easy to touch because it was through the packaging," "It was the first time I came to know that there are two types of muscles on a scallop." On the other hand, some suggestions pointed out areas of improvement and some of the points were difficult to interpret, such as "I wanted to see living fish" and "the image viewed on TV of science program is beautiful." One suggestion for the future was "It might be fun to do the course in the aquarium."

\section{DISCUSSION}

In our research, we used seafood to teach students about animal anatomy. Since it is possible to implement even without special laboratory facilities, anatomical education using marine products can also be pursued at home. Saiki and Okino (2014) showed students aversion towards anatomy practice. It is reported that the aversion for anatomy become an obstacle to learner's understanding of the inner structure of animals (Iwama et al., 2008; Koike and Takatsudo, 2012). In this lecture, students who used seafood, on the other hand, did not show the same aversion towards studying anatomy and observed the inner structure of marine animals with interest. We, therefore, recommend teaching animal anatomy using seafood, since it can be done without creating any feelings of aversion on the learner's part. The results of the questionnaire revealed that most participants responded with "excellent" or "good" to questions about impression and comprehension (Figures 7 and 8). Besides, most participants changed the impression of the inner structure of animals from "very bad" or "bad" to "excellent" or "good" (Figure 6). According to the results, using seafood as teaching material was very effective at helping students understand the anatomical structure of marine life without aversion. It is reported that hands-on learning is available for decreasing aversion for animals (Prokop and Fančovičová, 2016). Therefore, it is suggested that handson with marine products for primary anatomical education, which tends to be got aversion was excellent methods.

Anatomy is essential not only for professionals such as medicine and nursing but also for biological education (Iwama and Hatogai, 2010). However, university students and specialized students in medicine and nursing where human anatomy is essential are rarely experienced in animal dissection before high school graduation (Iwama and Hatogai, 2010; Nishikawa and Tsuruoka, 2007). Being interested in the internal structure of animals and knowing 
the mechanism of life, before leaving the university, it is desirable that they learn the basics of anatomical education (Iwama et al., 2008). Therefore, there is a need for opportunities to learn anatomy gradually from elementary school students (Iwama et al., 2008; Iwama and Hatogai, 2010). When learning about living things, observation, and experience are important (Shimada, 2009). Especially, hands-on learning is very active way to enhance more profound understanding and interest for learners (Brinson, 2015; Jones et al., 2019; Lempp, 2005; Lineberger and Jayne, 2000; Prokop and Fančovičová, 2016; Reid, 2001). Hand-on anatomical learning is very important since not only deep understanding by hand-on effect but also the opportunity of understanding "three-dimensional" structure of life. The book can only show the two-dimensional view through the structure of the organism is constructed with three-dimension (Tompson and Toga, 1996). Therefore, hands-on anatomical learning trumps book learning from these points: enable to observe with three-dimensional view (Jang et al., 2017; Tompson and Toga, 1996) and the spatial orientation within the body (Forum, 2004). Besides, an anatomical education is critical to understanding the inner structure of animals (Iwama and Hatogai, 2010). Since there are various considerations such as bioethics and emotional education (Saiki and Okino, 2014), it is only recently that it became possible for general children to study anatomy. Therefore, we would argue that studying animal anatomy using food materials, as was done in this course, could be useful.

The opportunity to learn about the body parts of those living beings we eat regularly is also a significant aspect of food education (Simada, 2015). Regarding fish fillets, although there is a recognition that they come from fish, it is difficult for students to understand that they are eating fish muscle, which is the result of dissecting the fish. Therefore, to enhance students' understanding of the anatomy and myology of fish, fish fillets may be a useful anatomical educational tool. Also noteworthy is students' limited awareness of the basic body structure of mollusks such as cephalopods and shellfish. Because fish have the basic structure of vertebrates (Romer, 1970), students are keenly aware of their internal organs and musculoskeletal forms. However, in this research, when it comes to mollusks, recognition decreases significantly. Mollusks have less aversion than that of vertebrates because there is no red blood, and individuals of optimal size for macroscopic dissection are easy to prepare with ingredients, which is useful for anatomical education of animals (Sasaki, 2008). Education focusing on the basic posture of invertebrates should be the focus of future work.

In this course, we used mainly lap and Ziploc bags for raw samples. As a result, students were comfortable touching the raw sample because it was through the outer layer. For the learner who is averse to touching raw fish or concerned about contamination, this seems to be a useful approach. Recently, the care for students of aversion in anatomical education is needed, and some educational materials were practiced (Saito, 2004). Saito (2004) mentioned the usefulness of human body model by plastination, which is clean and odorless. For those who wish to use their bare hands, this procedure is not necessary. However, particular care seems to be necessary for student who has an aversion for teaching rare samples and in the place of prohibiting vivid smell. Since hands-on activities can decrease children's disgust for animals (Prokop and Fančovičová, 2016), it may be important to make it easy for anyone to touch something that is not a good impression for first learners with knowledge alone.

In this study, we explored the usefulness of using marine products for educational purposes from an anatomical, functional morphological, and ecological point of view. While we used fishes, cephalopods, and shellfish this time around, in the future, it would be worthwhile to quantify the usefulness of different types of teaching material, to gain a detailed understanding of their effects and to use them in the field.

Although many students do dissection practice after from high school, to educate at an early stage by using the hands-on learning for deep understanding and reducing aversion to anatomy is desirable (Iwama and Hatogai, 2010). This research showed the positive effects of usage of marine products for hands-on anatomical learning to elementary school student. In the future, the researches on further advanced teaching materials and programs are needed for hands-on anatomical education is widely available.

\section{Compliance with Ethical Standards}

This work has no potential conflicts of interest.

About research involving Human Participants, permission to use data for this research was obtained from the subjects of experiment and guardians of the experiment subjects. Also, we gained permission from the ethical standards by this course place.

\section{REFERENCES}

Brinson, J. R. (2015). Computers \& Education Learning outcome achievement in non-traditional (virtual and remote) versus traditional (hands-on) laboratories: A review of the empirical research. Computers \& Education 87, 218-237. https://doi.org/10.1016/j.compedu.2015.07.003

Dinsmore, E. C., Daugherty, S. and Zeitz, J. H. (2001). Student responses to the gross anatomy laboratory in a medical curriculum. Clinical Anatomy, 14(3), 231-236. https://doi.org/10.1002/ca.1038 
Finkelstein, P. and Mathers, H. L. (1990). Post-traumatic stress among medical students in the anatomy dissection laboratory. Clinical Anatomy, 3(3), 219-226. https:/ / doi.org/10.1002/ca.980030308

Forum, D. (2004). New Path for Teaching Anatomy: Living Anatomy and Medical Imaging vs. Dissection. The Anatomical Record, 28(1B), 4-5. https://doi.org/10.1002/ar.b.20040

Funabara, D. (2009). The Molecular Mechanism of Catch Contraction in Bivalve Adductor Muscle. Journal of the Japan Welding Society, 78(3), 25-29. https://doi.org/10.2207/jjws.78.201

Furihata, S., et al. (2009). Learning through Experiencing Nature from the Standpoint of Environmental Education: Task and Forecast. Japanese Journal of Environmental Education, 19(1), 3-16. https://doi.org/10.5647/jsoee.19.1_3

Hosoyama, M. (2012) For Safe and Easy Science Experiment. Nagoya Journal of Space \& Earth Sciences, 42, 37-42.

Houwink, P. A., et al. (2004). Help of third-year medical students decreases first-year medical students' negative psychological reactions on the first day of gross anatomy dissection. Clinical Anatomy, 17(4), $328-333$. https://doi.org/10.1002/ca.10218

Iwama, J. and Hatogai, T. (2010). Curriculum Planning as Preparation for Specialized Study in College of Animal Dissection Education Educational Significance of Nursing. Journal of Research in Science Education, 34(1), 13-23.

Iwama, J., Hatogai, T., et al. (2008). Study on Educational Significance of "Dissection of Fish"- Aiming at Development of Teaching Materials for Forming Scientific Concept and Fostering View of Life-. Journal of Science Education in Japan, 32, 465-466.

Iwama, J., Matsubara, S. and Shimoji, T. (2008) State of Introducing Teaching Materials on Animals to Elementary School Science Textbooks Viewed from a Notion of Biodiversity: Aiming at Development of Science Textbooks Enhancing Children's Interest. Japan Society of Science Education, 32(1), 27-38.

Jang, S., et al. (2017). Computers \& Education Direct manipulation is better than passive viewing for learning anatomy in a three-dimensional virtual reality environment. Computers \& Education, 106, $150-165$. https:// doi.org/10.1016/j.compedu.2016.12.009

Jones, A. L., et al. (2019). Impacts of Hands-On Science Curriculum for Elementary School Students and Families Delivered on a Mobile Laboratory. Journal of Stem Outresearch, 2(January), 1-12. https://doi.org/10.15695/jstem/v2i1.02

Kajiwara, E., Kiyomura, N. and Kashima, S. (2008). Structure of the barrier factors and the need factors, which related to learning the knowledge of Nursing Human anatomy and physiology. Bulletin of Seinan Jo Gakuin University, 12, 37-46. https://doi.org/10.1108/13673270810852377

Kashio, S. (2016). An efective approach for fisheries and ocean education using boiled and dried small sardine (Chirimen Jako) -Let's collect “Chirimen Monster”!!_”. Nippon Suisan Gakkaishi, 82(40), 2016. https://doi.org/10.2331/suisan.WA2199-2

Kato, M. (2017). A Guide to a Relationship between Human and Animals in a Dissection Learning Activity in Elementary school and Secondary school. Journal of human studies, 53, 53-59.

Koike, M. and Takatsudo, S. (2012). A Case Study of a Science Class for Anatomy of Fish Using a Jigsaw Puzzle as a Teaching Tool. Japan Curriculum Research and Development Association, 34(4), 1-8.

Lempp, H. K. (2005). Perceptions of dissection by students in one medical school: beyond learning about anatomy. A qunlitative study. Medical Education, 2005(39), 318-325. https:/ / doi.org/10.1111/j.1365-2929.2005.02095.x

Lineberger, E. S. and Jayne, Z. M. (2000). School Gardens : Can a Hands-on Teaching Tool Affect Students' Attitudes and Behaviors Regarding Fruit and Vegetables? Hort Technology, 10(September), 593-597. https:/ / doi.org/10.21273/HORT'TECH.10.3.593

Nishikawa, K. and Tsuruoka, Y. (2007). The actual situation of animal dissection in the elementary and junior high school science classes. Japanese Journal of Biological Education, 47(4), 146-156.

Nozaki, M. and Katayama, T. (2017) Problems and Meanings about Anatomical Experiments in Science Class of the Secondary Education. Journal of Science Education in Japan, 32(5), 189-194.

Omura, A. (2016) Dissection and Observation of Penaeus monodon Approaches for the improvement of observation skills through sketching . Bulletin of Teikyo University of Science and Technology, 12, 155-160.

Prokop, P. and Fančovičová, J. (2016) The effect of hands-on activities on children's knowledge and disgust for animals. Journal of Biological Education, 51(3), 305-310. https: / doi.org/10.1080/00219266.2016.1217910

Reid, K. J. (2001). Outreach to K-12 Programs with a mobile laboratory: Hands-on electronics manufacturing. In the Frontiers in Education Conference, 2001. 31st Annual, Reno, NV. https://doi.org/10.1109/FIE.2001.964050

Romer, A. S. and Parsons, T. S. (1986). The Vertebrate Body (6th ed.) C. International (ed.), Philadelphia: Saunders College.

Saiki, H. (2017). Anatomical Exercise using "Boiled-Dried Fish"with regard to Structure and functions of the human body in 6th Grade Elementary School Science. Journal of Research in Science Education, 57(3), $237-280$. https://doi.org/10.11639/sjst.16052 
Saiki, H. and Okino, K. (2014). A Survey of Anatomical Exercise in the Lower Secondary School Science Classes and the Anatomical Exercise of "Groups of animals" by the 2nd Grade Lower Secondary School Science Hideto. Journal of Research in Science Education, 54(3), 347-356. https://doi.org/10.11639/sjst.13040

Saito, K. (2004). An Introduction to Anatomical Teaching Using the Plastinated Human Body. Structure and Function, 3(1), 17-21.

Sakashita, R., et al. (2004). Development of Teaching the Structure and Function of the Human Body in Nursing Educaion. CNAS Hyogo Bulletin, 11, 57-66.

Sasaki, T. (2008). Anatomy of the Mollusca: Sepia esculenta (Cephalopoda: Sepiidae), Turbo cornutus (Gastropoda: Turbinidae) and Patinopecten yessoensis (Bivalvia: Pectinidae). Fossils, 84, 86-95.

Shimada, H. (2009). Environmental Education Using Rock Shells in Lower Secondary Scool Science. Kumamoto University Repository System, 58, 1-6.

Simada, S. (2015) The Effect of Experimental Leaning by Gyoshoku Education on Eating Awareness and Habits Among Elementary School Children. Journal of Yasuda Woman's University, 44, 233-245.

Thompson, P. and Toga, A. W. (1996) A Surface-Based Technique for Warping 3-Dimentional Images of the Brain. IEEE Transactions on Medical Imaging, 15(4), 1-28. https:// doi.org/10.1109/42.511745

Wells, M. J. (1992). The cephalopod heart: The evolution of a high-performance invertebrate pump. Cellular and Molecular Life Sciences, 48(9), 800-808. https:/ / doi.org/10.1007/BF02118412 